\title{
Cognitive factors in addiction and nucleus accumbens function: Some hints from rodent models
}

\author{
ROY A. WISE \\ National Institute on Drug Abuse, Bethesda, Maryland
}

\begin{abstract}
Elevation of extracellular dopamine levels in the nucleus accumbens is important for both the initiation and the maintenance of cocaine and heroin seeking in animal models. Nucleus accumbens neurons fire in response to both the receipt and the expectancy of reward. The learning of drug selfadministration habits depends critically on the ability of the animal to learn associations between rewards and their environmental predictors, and such learning does not occur in accumbens-compromised animals. Reward-associated stimuli are also critical for the initiation of drug taking following periods of abstinence in trained animals. Reward-associated stimuli are also important in maintaining continued responding for these drugs, although once extracellular dopamine levels have become elevated by initial drug intake, subsequent drug self-administration becomes increasingly dominated by pharmacological factors, at least in rodent models. Initially rewarding drug injections appear to lose their rewarding effectiveness when dopamine concentration in the nucleus accumbens is elevated above some satiating level. When dopamine is depleted or dopamine function is impaired, the probability of response initiation decreases; rats do not appear to self-medicate depression of the reward system as humans have been suggested to do. This presumed difference between the two species may reflect cognitive functions unique to humans, such as insight gained from the observation of others and response biases conferred through language and culture. Thus, although they inform us regarding some cognitive factors in addiction and nucleus accumbens function, our animal models may inform us minimally about cognitive factors that are of major significance in humans.
\end{abstract}

Current thinking about nucleus accumbens function has been significantly influenced by studies of its roles in the self-administration of drugs and the reward of brain stimulation. Such studies suggest (1) some cognitive factors that contribute to motivated behaviors in a variety of mammalian species, (2) some cognitive factors that appear to contribute uniquely to human motivated behavior, and (3) one cognitive factor that may be less involvedeven in human motivated behavior-than has commonly been assumed. Some cognitive functions that are clearly implicated in the habits established by drugs of abuse and by rewarding the electrical stimulation of the brainevents thought to be rewarding because of their ability to elevate extracellular dopamine levels in the nucleus accumbens (Wise, 1978, 1988; Wise \& Bozarth, 1987)-are learning, memory, and expectancy. Among factors not implicated in the control of rodent drug self-administration are cognitive insights that require human intelligence (such as the insights into our own vulnerabilities that we derive from observing the fates of others) and response biases that are promulgated through language and human culture (the "voice" of human ideology). Such uniquely

Correspondence concerning this article should be addressed to R. A. Wise, Behavioral Neuroscience Branch, Intramural Research Program, National Institute on Drug Abuse, 5500 Nathan Shock Drive, Bethesda MD 21224 (e-mail: rwise@intra.nida.nih.gov). human cognitive factors may explain some aspects of addiction that are not shared with our mammalian cousins; one example may be self-medication of depression or withdrawal distress with drugs of abuse. Finally, one cognitive factor that may prove to play a less important role in drug seeking than has widely been assumed is the subjective experience of drug-induced pleasure or euphoria.

\section{Roles of Learning, Memory, and Reward Expectancy}

Expectancies based on learning and memory appear to play important roles in addiction and in nucleus accumbens function. The firing of nucleus accumbens medium spiny neurons and of the ventral tegmental dopaminergic neurons that innervate them are each affected not only by drug and food rewards but also by the sensed antecedents of such rewards (Apicella, Scarnati, Ljungberg, \& Schultz, 1992; Carelli, King, Hampson, \& Deadwyler, 1993; Chang, Janak, \& Woodward, 1998; Chang, Paris, Sawyer, Kirillov, \& Woodward, 1996; Chang, Sawyer, Lee, \& Woodward, 1994; Peoples \& West, 1996; Schultz, Apicella, Scarnati, \& Ljungberg, 1992; Schultz \& Romo, 1990). Indeed, as monkeys learn to anticipate food reward, their dopaminergic neurons come under control of stimuli predictive of a given reward and can cease to respond to the reward itself (Romo \& Schultz, 1990). Both the medium spiny neurons of the nucleus accumbens and the dopaminergic neurons of the ventral tegmental area 
are well situated to receive information about signals associated with reward expectancy; each receives excitatory glutamatergic inputs from a variety of cortical structures, including the medial prefrontal cortex, the hippocampus, and the amygdala. These glutamatergic inputs are potential carriers of information associated with set and setting that, along with pharmacological factors, contribute importantly to drug-seeking behavior; these structures are implicated in the effects of conditioned reinforcers (Everitt, Cador, \& Robbins, 1989; Meil \& See, 1997), contextual cues (Hirsh, 1974; Kesner \& Hardy, 1983; Sutherland \& McDonald, 1990), working memory, and the coordination of executive function (Goldman-Rakic, 1996; Goldman-Rakic, Bates, \& Chafee, 1992). Thus, the nucleus accumbens is well situated to play a role in a variety of aspects of cognition.

As is the case with all motivational theory, theories of drug seeking must deal with two issues: What determines the initiation of goal-directed behavior and what determines the maintenance of such behavior? A host of constructs have been offered for the two factors, and they usually come in pairs, such as pain and pleasure, the stick and the carrot, drive and reinforcement, wanting and liking. One member of each pair-pain, the stick, drive-is seen as being present prior to the initiation of goal-directed behavior and is often characterized as the major impetus for initiation of drug taking in addicts. The notion that all drives result from biological need states and that reinforcement results from biological need reduction (Hull, 1943) has been thoroughly discredited in experimental psychology (see, e.g., Fiske \& Maddi, 1961; Harlow, 1953; Hebb, 1955; Miller, 1963; Pfaffmann, 1960); however, the view that drug-induced neuroadaptations establish acquired tissue needs and that the states associated with such physiological needs are prime determinants of addiction (e.g., Hebb, 1949; Malmo, 1975) continues to thrive in addiction theory (e.g., Dackis \& Gold, 1985; Koob, Stinus, Le Moal, \& Bloom, 1989; Nestler \& Aghajanian, 1997; Robinson \& Berridge, 1993; Solomon \& Corbit, 1973). The renaming of drive as "opponent process" (Solomon \& Corbit, 1973), "craving" (Pickens \& Johanson, 1992), or "wanting" (Robinson \& Berridge, 1993) has given need states new life as a motivational construct in the addiction literature. This is unfortunate, because the corollary - the need-reduction hypothesisfosters the teleological notion that the animal behaves in order to alleviate its need state. This, in turn, implies that the animal "knows" what it is doing and why it is doing it. However, while physiological need reduction describes a consequence of a variety of motivated behaviors, it fails to offer an efficient cause - an event that reliably precedes and identifies when, within a period of relatively consistent tissue need, a particular goal-directed response will be initiated and executed (see Hinde, 1966, chapter 8).

A second and more cognitive motivational construct, incentive motivation, is also seen as an antecedent of goalseeking behavior. Incentive motivation is a state of be- havioral and cognitive arousal that is induced, when the animal is in an appropriate need state, by reward-associated environmental stimuli (Bindra, 1974); its cognitive correlate is thought to be reward expectancy, and its subjective labels include "craving" and "wanting." The effectiveness of incentive motivational stimuli in instigating behavior is posited to vary in proportion to appropriate need states. In this way incentive motivational theory offers an external but state-dependent trigger for motivated action. When a goal object is present and directly sensed, one can assume that the sense impression of the goal object itself both elicits and guides the subsequent behavior (Glickman \& Schiff, 1967; Schneirla, 1959). From this perspective, motivational states are seen as modulators of the effectiveness of the environmental incentives that guide the component acts rather than as elicitors of the behavior in their own right (Dethier, 1966; Mendelson, 1966; Morgan, 1974; Wise, 1987b). This postulate is necessitated by the fact that drive states are relatively continuous, whereas goal-directed responding is relatively episodic.

When the goal object itself is absent, goal-associated stimuli must trigger and guide the behavior (Bindra, 1974; Toates, 1986). However, when the hungry subject responds to a food stimulus that will satisfy the hungerassociated tissue need, it is tempting to suggest that the consequence of need reduction comes to control the behavior (Hull, 1943). The danger, of course, is teleology: attributing the behavior to its consequences rather than to its antecedents.

In the case of feeding, it is known that neither physiological need nor an associated drive is necessary for the initiation of a goal-directed act. Nor is drive necessary at the various choice points that an animal encounters between the initiation of foraging and the reaching of the goal. This has been clearly and elegantly shown by Mendelson (1966), who provided an experimenter-controlled state akin to hunger (Coons, Levak, \& Miller, 1965; Wise, 1974) by electrically stimulating the lateral hypothalamic medial forebrain bundle in sated rats being tested in a $\mathrm{T}$ maze with food reinforcement. Mendelson found that animals in the sated, nonstimulated, state would nonetheless run from the startbox and turn toward the food at the choice point if, on previous trials, they had received hunger-inducing stimulation and eaten food in the goalbox. That is, a history of stimulation-induced eating was all that was necessary in an otherwise unmotivated animal to motivate both response initiation in the startbox and food-directed turning at the choice point. A stimulation-induced drive state was necessary at neither point, as long as the animals had the expectancy of food and a history of receiving that food in an appropriate drive state once they reached the goalbox. Without the history of stimulation-induced drive and feeding in the goalbox, animals left the startbox less reliably and tended to alternate between the baited and the nonbated arms at the choice point. Without learned expectancy of drive plus food in the goalbox, the goal-directed behavior was not learned and was not subsequently performed, even when 
the stimulation (drive) was given both in the startbox and at the choice point. Thus neither drive in the startbox nor drive at the choice point was necessary or sufficient to establish food-rewarded maze habits or to motivate their performance. Drive given with the food and only in the goalbox-after the initiation of running and after the occurrence of the correct choice-was sufficient to establish and maintain such habits. Thus there is reason to think that while drive is not important for the initiation of goal-directed acts, it is important for their maintenance (Bindra, 1974; Mendelson, 1966). With respect to the cognitive correlates of motivated behavior, this view is incompatible with the notion that awareness of need is important for response initiation but is compatible with the notion that expectancy of reward is important for response initiation.

This counterintuitive point has been illustrated objectively in additional ways. Morgan (1974) drew similar conclusions from analysis of the behavior of animals that were trained to leverpress under conditions of deprivation but were then tested under conditions of satiety. Despite their current lack of interest in free food, such animals leverpress for earned food when put in the apparatus where they have previously worked for food when hungry. This behavior decreases progressively within test sessions, much like the behavior of a hungry animal tested under conditions of nonreward. That is, in each case, the response habit "extinguishes." Moreover, if such animals are tested on more than one occasion, the behavior (which recurs spontaneously, though to a progressively lesser extent, on subsequent days) extinguishes more rapidly from one session to the next. Morgan likened this to the decreased resistance to extinction seen when previously trained animals are tested several times under conditions of nonreward. Such sated animals are initially sufficiently habit bound as to eat the food despite the fact that they ignore free food when it is concurrently available (Carder \& Berkowitz, 1970; Davidson, 1971; Jensen, 1963). Stressing the similarities, Morgan termed the continued work when subjects were not deprived as "resistance to satiation." What is implied is a conclusion similar to Mendelson's: that the animal must learn, from sensory exposure, that food is not reinforcing during periods of satiety.

In these experimental settings when drive is not present, food-directed behavior must necessarily be elicited by conditioned cues. These environmental cues have acquired significance for the animal because of their prior association with the combination of (1) the drive state of hunger with (2) the goal object of food. In these laboratory examples where there was no internal drive state when the behaviors were initiated, the behaviors would clearly not have occurred had the animals lacked histories of drive and reinforcement in the testing apparatus. Incentive motivational theories of instrumental behavior (Bindra, 1974; Toates, 1986) hold that reinforcement-associated stimuli trigger the initiation of all goal-directed habits, and that the importance of drive states is to make reinforcing (Mendelson, 1966) or salient (Dethier, 1966; Robinson \& Berridge, 1993) stimuli that would otherwise be neutral in valence, as is food when we are sufficiently sated. If internal states are occasion setters or discriminative stimuli for - rather than elicitors of - motivated behavior, we must acknowledge reward-associated stimuli in the environment-or, more precisely, perceived reward-associated stimuli - as the momentary triggers for responding under the relatively constant conditions of the appropriate internal state (Bindra, 1974; Dethier, 1966). The episodic nature of feeding in the presence of food, in this view, can be attributed to the episodic perception of available food as the animal moves its eyes, head, and body in a given situation. Although rewardassociated stimuli need not trigger cognitive awareness, their significance clearly derives from learning and memory, functions closely associated with cognition.

Consistent with the view that the memory-dependent impact of reward-associated stimuli rather than the presence of an aversive drive state initiates goal-directed behavior, Gallistel and colleagues (Gallistel, Stellar, \& Bubis, 1974) have shown quite elegantly that the strength of motivation on a given runway trial is at least partially a function of memory for past reward. The Gallistel task links learning and memory to brain pathways that are assumed to project, perhaps across a few synapses, to the nucleus accumbens (Wise \& Rompré, 1989; Yeomans, Mathur, \& Tampakeras, 1993). In the Gallistel et al. (1974) task, rats are allowed to traverse a runway to a chamber where they can leverpress for rewarding lateral hypothalamic electrical stimulation that is independent of a deprivation-induced biological need. Here, the running speed on a given trial is determined almost entirely by two identified factors: a memory-independent factor and a memory-dependent factor. The memory-independent factor arises from priming stimulation that the animal is given just before being placed in the start-box of the runway. The stronger and the more recent the priming stimulation, the faster the animal runs to the goalbox. This contribution to response initiation is a drive-like contribution, but it depends on presentation of rewarding stimulation rather than on its absence; that is, the drive state is strongest immediately after the stimulation, and it decreases as the animal is "deprived" of further stimulation. The effect of this response-independent "priming" stimulation does not get coded in long-term memory; it decays in seconds or tens of seconds (Gallistel, 1969; Gallistel et al., 1974). One or two minutes after priming stimulation, the running speed of the animal will be no different than it would had priming never been given.

The memory-dependent factor, on the other hand, is proportional to the strength of the response-contingent reward that has been given in the goalbox on the previous four or five trials, regardless of whether this reward was earned a few seconds or a few days earlier. On a given trial under conditions of fixed priming, the animal runs faster if its most recent few rewards in the goalbox were strong and runs slower if its last few rewards were weak. Be- 
cause this motivational effect of stimulation-unlike the priming effect-does not decay for days, Gallistel et al. (1974) identify this factor with a "memory-dependent" process. Note that this contribution to response initiation exerts its effects in the startbox and in the runway, prior to the rewarding event that it precedes. Thus it is an incentive motivational contribution.

The role of memory-dependent processes in the initiation of motivated acts is the substance of incentive motivational theory, where environmental cues associated with past reward are seen as the instigators of behavior (Bindra, 1974). Such processes are necessary in order to explain the behavior of Mendelson's (1966) animals that run in the absence of the usual lateral hypothalamic electrical stimulation and Morgan's (1974) animals that leverpress for food and eat food in the absence of the food deprivation that was present during training. That these animals run and leverpress when not hungry-only because they have been reinforced for doing so when they were hungry-illustrates the importance of habit as a source of motivation.

Although the neurobiology of operant learning remains to be elucidated (Cook, Stopfer, \& Carew, 1991; Stein, Xue, \& Belluzzi, 1994), the glutamatergic inputs to the nucleus accumbens, mentioned earlier, would appear to be likely candidates for important roles. Operant conditioning of single-cell firing patterns has been demonstrated in hippocampal tissue (Stein et al., 1994) and the hippocampus is implicated in contextual learning while the amygdala and the prefrontal cortex - additional sources of glutamatergic input to the nucleus accumbens-have been suggested to play roles in aspects of reward-associated cue learning and working memory, respectively.

Clinicians and addicts tend to endorse with some enthusiasm the notion that the addicted brain has been subjected to neural adaptations that distinguish it from the normal brain (Kosten, 1998); such adaptations clearly do develop (Markou \& Koob, 1991; Nestler \& Aghajanian, 1997). Moreover, it is clear that drug experience, even if brief, can cause relatively permanent (Cochin \& Kornetsky, 1964; Robinson \& Becker, 1986) alterations in sensitivity to the drug itself. The long-term consequences of repeated drug administration are tolerance or decreased drug sensitivity in some cases and sensitization or increased drug sensitivity in others. It is not clear, however, how such changes in drug sensitivity, which are usually produced in the laboratory by experimenter-administered rather than by self-administered injections, affect subsequent drug seeking and drug taking.

Addiction is a phenomenon of drug self-administration; it is compulsive drug seeking behavior, not simply drug dependence, that defines addiction (Jaffe, 1985). Surely the most significant difference between the addict and the nonaddict are differences in what the addict has learned and remembers about prior drug experiences. The brain of the addict contains memories of how to obtain and take the drug, of the subjective dimensions of the drug experience, and of the myriad associations between drug and environment. These are the constant reminders that keep the addict - at least while drug deprived in the drugassociated environment - from thinking of much that is not associated with the drug. The addict also has remembered knowledge about what side effects to expect and about which of society's teachings about a given drug are exaggerated and which are well founded. The addict has memories for drug-associated landmarks. In order to take the habitual drug, the addict must either be in a familiar and drug-associated place or must find features of the unfamiliar place that give clues about where to find drugs or where to find the kind of person that can give directions to drugs. The addict does not reach for the box that contains the syringe without knowledge of where the box is and without a remembered association of the visible box with the unseen syringe inside. It is sensory cuesthe box or stimuli that point to the box-rather than an internal need state that indicate which direction to turn and how far to move to find the box that contains the syringe. It is sensory cues that indicate where to go to find the bag that contains the drug or to find the individual that will sell the drug. As discussed in the context of the Mendelson experiment, these sensory cues not only give direction to the addict's actions; they induce - in the presence of discriminative internal cues associated with a drug-free or a drug-waning state- the motivation to take the drug. In a different setting, the motivation to take the drug is minimal even in detoxified addicts (Robins, Helzer, \& Davis, 1975). Thus it is largely knowledge of the significance of drug reward-associated sensory cues-a cognitive factor - that most importantly distinguishes the addicted brain from the nonaddicted brain. Just as the words "Do you want to go for a walk?" can trigger, in a trained dog, a frenzy of motivational excitement, so can the sights and sounds associated with prior drug taking move the addict to a state of anticipatory arousal and craving (Childress et al., 1999). The same sights and sounds have no meaning for the individual lacking a history of drug taking. Thus from one important perspective it is the engrams of drug-associated knowledge that constitute the primary difference between the addicted and the nonaddicted brain.

\section{Self-Medication:}

\section{A Largely Human Phenomenon?}

If it is cognitive, memory-dependent factors more than physiological withdrawal distress that trigger initiation of drug seeking and other goal-seeking behaviors, what is the importance of drug dependence or druginduced neuroadaptations in addiction? One possibility is that awareness of needs and how to alleviate them play a more prominent role in human than in rodent behavior.

Behavioral pharmacologists, schooled in the teachings of Skinner, have generally eschewed the explanation of drug self-administration in terms of what Skinner labeled "mental causes." Rather, they have looked for the sources of control of drug seeking behavior in the animals' immediate environment, pharmacological and reinforcement 


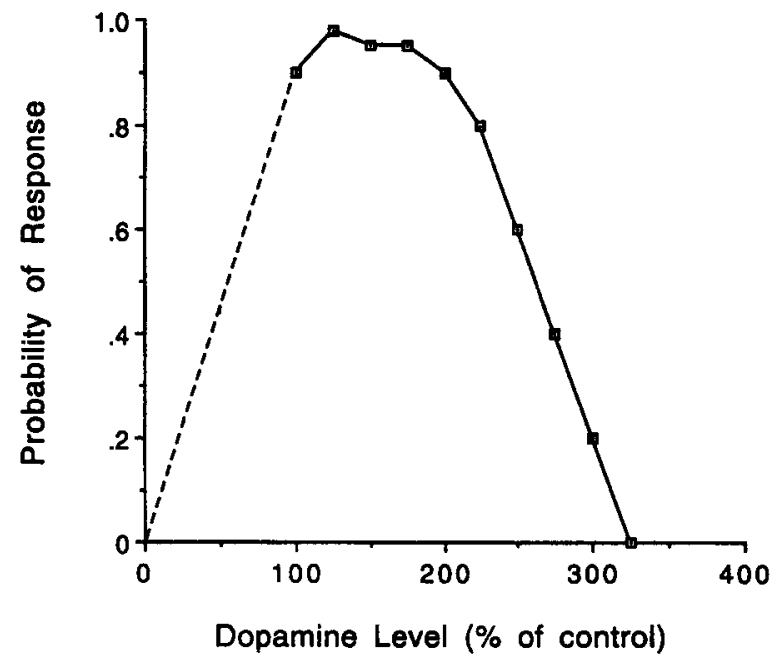

Figure 1. Estimated probability of leverpressing within the next $\mathbf{5}$ min as a function of momentary dopamine level in the nucleus accumbens. The solid line reflects dopamine estimates based on microdialysis samples taken from nucleus accumbens within self-administration sessions. The dotted line for values of dopamine below $100 \%$ of control values reflects the fact that only postmortem data are available for estimating over this range.

history, and current drug state. From this frame of reference they have established animal models of drug selfadministration that inform us about the components of our susceptibility to drugs of abuse that we share with other mammalian species. The obvious limitations of these models is that they tell us nothing about the potential roles of human insight and hypothesis formation or of human cultural factors such as the communications of information and misinformation about addiction through human language.

The prototypical animal models of addiction involve the intravenous self-administration of opiates and psychomotor stimulants. Typically, primates, dogs, rats, or mice are allowed to leverpress for intravenous injections of these drugs for a limited time each day. In the simplest models, where each leverpress results in a moderate injection, the animals tend to respond quickly for the first few injections (during what is termed the "loading phase" of the session) and then settle into a pattern of regularly spaced leverpressing (termed the "maintenance phase") that is maintained for several hours or until the drug becomes unavailable (Pickens \& Harris, 1968).

In the maintenance phase of such sessions, the behavior appears to be largely under the control of pharmacological factors. Over a wide range of injection doses and a wide range of response requirements, the animal adjusts its rate of responding such that relatively constant hourly drug intake is maintained (Pickens \& Thompson, 1968; Yokel \& Pickens, 1973). If metabolism of the drug is accelerated or decelerated, response rate increases or decreases proportionally (Dougherty \& Pickens, 1974). If the dose per injection is unpredictably varied within ses- sions, latency to leverpress for the next injection is proportional to dose of the last injection (Gerber \& Wise, 1989). When responding for $d$-amphetamine, rats respond each time their blood concentration falls to approximately $0.2 \mu \mathrm{g} / \mathrm{ml}$ (Yokel \& Pickens, 1974). Falling levels of nucleus accumbens dopamine, caused by falling levels of amphetamine in the blood, also reliably predict withinbinge leverpressing for intravenous cocaine (Wise et al., 1995), amphetamine (Leeb \& Wise, 1994), and heroin (Pocock, Leeb, \& Wise, 1994). There seems no need to invoke cognitive factors to explain the maintenance of leverpressing within such sessions; the behavior is adequately predicted from the animal's immediate reinforcement history and knowledge of the metabolic half-life of the drug (Yokel \& Pickens, 1973). It is tempting to use the term "behavioral homeostasis" and "set-point" to refer to such phenomena, though these terms do not explain anything but rather merely denote the mysteries to be explained. It is the immediate and historical antecedents of each leverpress-including the subject's memories and expectations - that offer the seeds of explanation.

From studies in which multiple brain microdialysis samples are taken in the time between injections, we can estimate the probability of responding for the next injection as a function of momentary nucleus accumbens dopamine levels. The estimated probability of responding for additional cocaine within the next $5 \mathrm{~min}$ is shown for 4 animals as a function of their momentary dopamine levels in Figure 1. When basal dopamine levels are "normal" (at the beginning of each day's 4-h test session), the probability of responding is high but significantly less than one. The probability of responding increases to almost one, however, if dopamine levels are elevated (1) by giving a moderate "priming" dose of cocaine (de Wit \& Stewart, 1981; Gerber \& Stretch, 1975) and thus elevating dopamine levels by prolonging its extracellular half-life (Heikkila, Orlansky, \& Cohen, 1975), (2) by giving a ventral tegmental morphine injection (Stewart, 1984) and thus elevating dopamine levels by disinhibiting the firing of dopaminergic cells (Johnson \& North, 1992), or (3) by stressing the animal with footshock (Erb, Shaham, \& Stewart, 1996; Shaham, Rajabi, \& Stewart, 1996; Shaham \& Stewart, 1995) and thus elevating dopamine cell firing by stress (Keefe, Sved, Zigmond, \& Abercrombie, 1993). "Priming" animals by giving free injections is a method used frequently to induce animals to begin "loading" at the beginning of a test session. Once dopamine levels are slightly elevated by any of these methods, the probability of responding increases to almost one and remains high until blood levels of drug and nucleus accumbens levels of dopamine are sufficiently elevated.

Under conditions of unlimited psychomotor stimulant availability, animals usually remain intoxicated for hours or even days before pausing for variable periods of sleep and other activities (Bozarth \& Wise, 1985; Johanson, Balster, \& Bonese, 1976; Pickens \& Harris, 1968). Once a period of abstinence is initiated, it is difficult to predict when drug taking will be "spontaneously" resumed. Once 
the animals have paused long enough for blood levels of a drug to fall to zero (and for dopamine levels in the nucleus accumbens to fall to normal), the probability of responding drops again to something considerably below one. Periods of spontaneous abstinence can usually, however, be terminated by another priming injection of the drug (Pickens \& Harris, 1968). Thus, during periods of spontaneous abstinence, as in the case of periods of imposed abstinence, the probability of responding is less than one unless dopamine levels are elevated by priming. That is to say, laboratory rats do not appear to selfmedicate depression of the reward system-between binges - by initiating drug seeking behavior.

As dopamine levels are elevated, however-either by multiple injections in the loading phase or by single injections in the maintenance phase-the probability of responding for additional drug falls off precipitously (Figure 1). This is not because high levels of the drug (or of dopamine) are aversive; animals given the choice between larger and smaller doses tend to prefer the higher doses (Iglauer, Llewellyn, \& Woods, 1976) if they have a dose preference at all (Yokel, 1987). Rather, it appears that high levels of these drugs are satiating and that the injection of additional drug is no longer reinforcing. Thus the tendency to respond closely on the heels of an earlier response drops out progressively as the self-administration habit is acquired. That is, the animals appear to learn not to respond frequently after having done so in the early stages of training. It would appear that the tendency to respond during periods of high blood levels of drug (and nucleus accumbens levels of dopamine) drops out as the animal comes to discriminate the state associated with low dopamine levels from the state associated with satiating dopamine levels. If there were a cognitive correlate of this learning, it would be conscious knowledge that additional drug is not rewarding when dopamine levels are already elevated.

These facts seem to contradict the common view of addiction, formalized as "opponent-process theory" (Solomon \& Corbit, 1973), which holds that the craving for a drug and the probability of taking it should be strongest during periods of drug privation (when dopamine levels are low) rather than during periods when dopamine levels are elevated above normal by priming injections of the drug. The view that it is a "taste" of the drug or an exposure to drug-associated stimuli that provokes drug craving has been termed a "proponent-process" theory (Stewart \& Wise 1992). This view is consistent with the fact that human alcoholics tend, between binges, to undergo the period of maximal withdrawal distress without, literally, lifting a finger (preparataory to leverpressing) to self-medicate their withdrawal distress with alcohol, only to begin another binge when withdrawal distress has decreased to minimal levels (Mello \& Mendelson, 1972). The proponent process theory and the alcohol findings are, however, inconsistent with what addicts tend to tell clinicians-namely, that it is withdrawal distress (particularly in the case of opiates and more re- cently in the case of psychomotor stimulants) that causes the reportedly unendurable cravings that make drug taking compulsive and no longer merely recreational.

There is little direct evidence that can be brought to bear on the question of the probability of drug seeking when dopamine levels are below normal (for this reason this portion of the probability function in Figure 1 is shown as a dotted line). It is well known that lesions that reduce striatal dopamine by $80 \%$ or more leave animals aphagic, adipsic, and akinetic (Zigmond \& Stricker, 1989). Following major dopamine depletions, rats no longer respond for intravenous cocaine (Lyness, Friedle, \& Moore, 1979; Roberts \& Koob, 1982; Roberts, Koob, Klonoff, \& Fibiger, 1980). The behavioral states of animals partially depleted of dopamine following withdrawal from psychomotor stimulants, opiates, or alcohol or following inescapable shock or treatment with dopamine antagonists are characterized variously as "anhedonia" (Markou \& Koob, 1991; Wise, 1982; Wise, Spindler, deWit, \& Gerber, 1978), "apathy" (Carboni, Leone, \& Di Chiara, 1989), or "behavioral despair" (Rossetti, Hmaidan, Laj, \& Gessa, 1992). While animals partially depleted of dopamine by treatment with the neurotoxin 6-hydroxydopamine (Roberts, Corcoran, \& Fibiger, 1977) or with dopamine systems partially blocked by dopamine antagonists (de Wit \&Wise, 1977; Ettenberg, Pettit, Bloom, \& Koob, 1982; Richardson, Smith, \& Roberts, 1994; Yokel $\&$ Wise, 1975) take more drug per hour than normal animals once they are primed or loaded, this would appear to be a reflection of the inability of the drug to satiate or satisfy the animals (Wise, 1987a) rather than a reflection of an increased willingness to initiate drug taking in the unintoxicated state. On the contrary, attenuation of reward function by dopamine antagonists or naloxone reduces rather than elevates the probability of initiating a heroin-trained response during a period of extinction in an animal model of reinstatement of or "relapse" to drug taking (Stewart \& Wise, 1992). Thus once trained laboratory rats have initiated a binge of drug taking, the impairment of reward function causes increased drug intake, whereas in drug-free animals - even those that compulsively self-administer the drugs once they start a bingethe impairment of reward function appears to decrease the probability of initiating a binge (Figure 1 ).

How might we reconcile the suggestion that rats do not seem to self-medicate during periods of withdrawal distress with the subjective reports of humans who are assumed to do so? One possibility is that humans are different from other mammals in this regard. Two possibilities relevant to cognition and nucleus accumbens function are of particular interest.

First, humans have implicit knowledge of the selfmedication model, passed on to them through the arguably unique tool of human language. Children and parents alike are taught that withdrawal distress is the hallmark of addiction and that it causes drug cravings that are almost unendurable. This hypothesis is often treated - even within many scientific circles-as if it were a self-evident 
truth, and it is supported frequently by the self-reports of some (but not all) addicts. Here is a cognitive factor that almost certainly biases the way in which the addict comes to describe and even to understand his/her own drug cravings. The self-medication model must certainly contribute to the perception and interpretation of drug craving in addicts. Indeed, the self-medication model may contribute to our perceptions of addiction as powerfully as, millennia ago, the then current model contributed to the then self-evident perception that the world was flat. The model could influence the human addict's understanding of drug cravings in two ways: It could inform the addict that drug taking can relieve even mild withdrawal symptoms and it could also drive the addict's referral of drug craving to withdrawal distress. It is almost paradoxical that Freud's insight that humans often misunderstand their own motivations and behavior is so rarely brought to bear on the addict's self-reports of drug cravings.

Even in the absence of linguistic teachings, humans might be much more likely to self-medicate than other mammals are. Humans are known to self-medicate other distress symptoms, taking, for example, aspirin for headache. Perhaps humans have-and perhaps rodents do not have-sufficient intelligence to figure out for themselves that drug taking relieves withdrawal distress. Perhaps the mental abilities of humans are sufficient to generate insights and expectancies about medication of withdrawal symptoms that do not occur to the rodent in distress.

A third possibility, of course, is that cognitive factors are merely correlates of drug seeking even in human addicts, and that-insight or not-those addicted to other drugs are, like the binge alcoholic and the nondependent rodent or primate (Bozarth \& Wise, 1984; Deneau, Yanagita, \& Seevers, 1969; Woods \& Schuster, 1971), more influenced by the carrot of drug reinforcement than by the stick of withdrawal distress (Wise, 1988).

\section{Are Hedonic and Reinforcing \\ Effects of Drugs Homologous?}

It has been argued that the ability of various rewards to activate the dopamine system accounts for the behavioral control that these rewards exert (Bozarth \& Wise, 1981; Di Chiara \& Imperato, 1988; Wise, 1978; Wise et al., 1978; Yokel \& Wise, 1975). It has further been suggested that dopaminergic activation may, within limits, be correlated with subjective pleasure (Volkow et al., 1997; Wise, 1982; Wise et al., 1978). Studies of human addicts, however, now offer a significant challenge for the view that rewarding drugs control behavior in proportion to the subjective pleasure or euphoria they induce.

The finding is that while cocaine maintains very consistent control over behavior, controlling intravenous self-administration rates that are largely invariant over hours within sessions in both humans (Foltin \& Fischman, 1991) and rodents (Pickens \& Thompson, 1968), the hedonic impact of these agents undergoes tolerance with repeated injections within sessions (Foltin \& Fischman,
1991). While within-session or "acute" tolerance to the response-controlling effects of intravenous cocaine can be produced by massive doses of cocaine (EmmettOglesby \& Lane, 1992; Li, Depoortere, \& EmmettOglesby, 1994), there is little evidence of such tolerance within sessions where the animal self-selects its own doses and is given access to the drug for only a few hours per day. On the other hand, tolerance to subjective pleasure from intravenous cocaine can develop within one or two self-administered injections in humans. Despite such tolerance to its subjective effects, humans continue to take these drugs at the same regular pace within a session, rather than accelerating their intake to maintain a constant euphoria level. The prevalence of acute tolerance to the subjective but not the behavior-controlling effects of cocaine appears to dissociate the subjective pleasure from the objective reward produced by this drug.

One hypothesis to deal with this dissociation would be that we have no conscious awareness of the phenomenon of reinforcement but that, pressed (by others but also by ourselves) to account for our own behavior, we refer it to the most salient cognitive correlate we can identify. Ignoring the times when the euphorigenic effects of the drug are weak, we attribute our continued traffic with the drug to the euphoric effects that we remember from the high points of our reinforcement history. Such a hypothesis might help explain the smoker who puts out an afternoon cigarette saying it tastes bad only to light another. In this view, the drug maintains the behavior, but it does not maintain the subjective effect that was experienced in response to the same dose earlier in the day. If this view has any merit, it suggests that the nucleus accumbens may play a greater role in the behavioral phenomenon of reinforcement than in the cognitive phenomenon of pleasure.

\section{Cognitive Functions of Nucleus Accumbens}

The facts that learning, memory, and expectation alter nucleus accumbens cellular activity and influence the behaviors that depend on nucleus accumbens function do not, of course, mean that the nucleus accumbens serves cognitive functions in any direct way. It appears to be the case, however, that the mesolimbic dopamine projection to the nucleus accumbens is activated not only by reward but also by drive and stress. Stimulation of the medial forebrain bundle fibers that are thought to trans-synaptically activate the mesolimbic dopamine system is not only rewarding in its own right; it also causes a hunger-like drive state (Wise, 1974). The evidence that both drive and reward are caused by the same medial forebrain bundle stimulation is not only that stimulation at the same loci cause both drive-like and rewarding effects (Margules \& Olds, 1962), but also that the fibers involved in the two functions have the same ranges of refractory period and conduction velocity and conduct in the same direction (Gratton \& Wise, 1988a, 1988b). In addition, mu and delta opioid injections, each of which increases dopamine release in the nucleus accumbens (Devine, Leone, Pocock, $\&$ Wise, 1993), are both rewarding in their own right (Bozarth \& Wise, 1981; Devine 
\& Wise, 1994) and induce or augment feeding (Jenck, Quirion, \& Wise, 1987; Noel \& Wise 1993, 1995). The fact that the same dopamine-activating electrical or chemical stimulation of the medial forebrain bundle can cause both drive-like and rewarding effects is known as the "drive-reward paradox"; why should an animal work for stimulation that will make itself hungry?

Whatever its explanation, the fact that animals will work for drive-like activation of the mesolimbic dopamine system makes it clear that dopaminergic function plays some very general role in motivated behavior, contributing something common to what are thought of as two very different motivational effects with two very different cognitive consequences. Dopamine contributes something common to both the stick and the carrot of motivational influences. Dopaminergic activation could, for example, contribute some form of attention-sharpening arousal that is common to the agitation associated with drive states and to the excitement associated with the anticipation and receipt of rewards. If this view has merit, it is unlikely that dopamine will be associated uniquely with any single cognitive function but rather likely that dopaminergic arousal will contribute generally to several such functions.

\section{Summary and Conclusions}

The nucleus accumbens appears to play pivotal roles in the goal-directed behavior that defines addiction, and there appear to be both cognitive and noncognitive contributions to these roles. The initiation and guidance of drug seeking responses is clearly dependent on environmental stimuli that to the animal have a learned significance. The most important of these stimuli appear to be those that have been previously associated with drug reward. Physiological state variables are also thought to contribute to response initiation, though their role is not proven and, at best, seems modulatory.

The maintenance of drug taking - the continuation of responding for drugs during extended periods of intoxication-seems more directly controlled by pharmacological factors, though reward-associated stimuli are still critical (rats working for intravenous drug injections can only approach drug-associated stimuli; because they do not know the locus of the drug in external space, they cannot approach the drug itself). Even here, however, where pharmacological and physiological factors appear to dominate the behavior, learned incentives and learning and memory play critical roles. The regulation of drug intake develops with days or weeks of repeated testing, and the animals apparently learn not to respond while brain dopamine levels are more than modestly elevated. Thus, cognitive factors - to the degree that learning and memory identify cognitive factors - play very important roles in addiction. Animal studies implicate the nucleus accumbens in the control of drug taking by drug-associated stimuli, both in the initiation and in the maintenance of drug self-administration binges.
Cognitive factors that appear to play minimal roles in lower animal addiction but that may play more substantial roles in human addiction -culturally transmitted belief systems, insights as to how to alleviate physiological need states, and subjective states of craving and euphoriamay depend critically on nucleus accumbens function but may arise at higher levels of the nervous system and may be represented minimally in rodents and lower primates.

\section{REFERENCES}

Apicella, P., Scarnati, E., Ljungberg, T., \& Schultz, W. (1992). Neuronal activity in monkey striatum related to the expectation of predictable environmental events. Journal of Neurophysiology, 68, 945-960.

BINDRA, D. (1974). A motivational view of learning, performance, and behavior modification. Psychological Review, 81, 199-213.

BOZARTH, M. A., \& WISE, R. A. (1981). Heroin reward is dependent on a dopaminergic substrate. Life Sciences, 29, 1881-1886.

BoZARTH, M. A., \& WISE, R. A. (1984). Anatomically distinct opiate receptor fields mediate reward and physical dependence. Science, 224, 516-518.

BozarTh, M. A., \& WISE, R. A. (1985). Toxicity associated with longterm intravenous heroin and cocaine self-administration in the rat. Journal of the American Medical Association, 254, 81-83.

Carboni, E., Leone, P., \& Di Chiara, G. (1989). SCH 23390 blocks drug-conditioned place-preference and place-aversion: Anhedonia (lack of reward) or apathy (lack of motivation) after dopaminereceptor blockade? Psychopharmacology, 99, 151-155.

CARDER, B., \& Berkowitz, K. (1970). Rats' preference for earned in comparison with free food. Science, 167, 1273-1274.

Carelli, R. M., King, V. C., Hampson, R. E., \& Deadwyler, S. A. (1993). Firing patterns of nucleus accumbens neurons during cocaine self-administration in rats. Brain Research, 626, 14-22.

Chang, J. Y., JANaK, P. H., \& WoOdWard, D. J. (1998). Comparison of mesocorticolimbic neuronal responses during cocaine and heroin self-administration in freely moving rats. Journal of Neuroscience, 18, 3098-3115

Chang, J. Y., Paris, J. M., SaWyer, S. F., Kirillov, A. B., \& WoodWARD, D. J. (1996). Neuronal spike activity in rat nucleus accumbens during cocaine self-administration under different fixed-ratio schedules. Neuroscience, 74, 483-497.

Chang, J. Y., SaWyer, S. F., LeE, R. S., \& Woodward, D. J. (1994) Electrophysiological and pharmacological evidence for the role of the nucleus accumbens in cocaine self-administration in freely moving rats. Journal of Neuroscience, 14, 1224-1244.

Childress, A. R., Mozley, P. D., McElgin, W., Fitzgerald, J., ReIvich, M., \& O'Brien, C. P. (1999). Limbic activation during cueinduced cocaine craving. American Journal of Psychiatry, 156, $11-$ 18.

Cochin, J., \& Kornetsky, C. (1964). Development and loss of tolerance to morphine in the rat after single and multiple injections. Jour nal of Pharmacology \& Experimental Therapeutics, 145, 1-10.

COOK, D. G., STOPFER, M., \& CAREW, T. J. (1991). Identification of a reinforcement pathway necessary for operant conditioning of head waving in Aplysia californica. Behavioral \& Neural Biology, 55, 313337.

Coons, E. E., LevaK, M., \& Miller, N. E. (1965). Lateral hypothalamus: Learning of food-seeking response motivated by electrical stimulation. Science, 150, 1320-1321.

DACKIS, C. A., \& GoLD, M. S. (1985). New concepts in cocaine addiction: The dopamine depletion hypothesis. Neuroscience \& Biobehavioral Reviews, 9, 469-477.

Davidson, A. B. (1971). Factors affecting keypress responding by rats in the presence of free food. Psychonomic Science, 24, 135-137.

Deneau, G., Yanagita, T., \& SeEvers, M. H. (1969). Self-administration of psychoactive substances by the monkey: A measure of psychological dependence. Psychopharmacologia, 16, 30-48. 
DETHIER, V. G. (1966). Insects and the concept of motivation. Nebraska Symposium on Motivation, 14, 105-136.

Devine, D. P., Leone, P., Pocock, D., \& Wise, R. A. (1993). Differential involvement of ventral tegmental mu, delta, and kappa opioid receptors in modulation of basal mesolimbic dopamine release: In vivo microdialysis studies. Journal of Pharmacology \& Experimental Therapeutics, 266, 1236-1246.

DEVINE, D. P., \& WISE, R. A. (1994). Self-administration of morphine, DAMGO, and DPDPE into the ventral tegmental area of rats. Journal of Neuroscience, 14, 1978-1984.

DE WIT, H., \& STEWART, J. (1981). Reinstatement of cocaine-reinforced responding in the rat. Psychopharmacology, 75, 134-143.

DE WIT, H., \& WISE, R. A. (1977). Blockade of cocaine reinforcement in rats with the dopamine receptor blocker pimozide but not with the noradrenergic blockers phentolamine or phenoxybenzamine. Canadian Journal of Psychology, 31, 195-203.

Di Chiara, G., \& Imperato, A. (1988). Drugs abused by humans preferentially increase synaptic dopamine concentrations in the mesolimbic system of freely moving rats. Proceedings of the National Academy of Sciences, 85, 5274-5278.

DOUGHERTY, J. D., \& PiCKENS, R. (1974). Effects of phenobarbital and SKF 525A on cocaine self-administration in rats. Drug Addiction, 3 , $135-143$

Emmett-OGLesby, M. W., \& LANE, J. D. (1992). Tolerance to the reinforcing effects of cocaine. Behavioural Pharmacology, 3, 193-200.

ERB, S., Shaham, Y., \& Stewart, J. (1996). Stress reinstates cocaineseeking behavior after prolonged extinction and a drug-free period. Psychopharmacology, 128, 408-412

Ettenberg, A., Pettit, H. O., Bloom, F. E., \& Koob, G. F. (1982) Heroin and cocaine intravenous self-administration in rats: Mediation by separate neural systems. Psychopharmacology, 78, 204-209.

EveritT, B. J., CADOR, M., \& RobBins, T. W. (1989). Interactions between the amygdala and ventral striatum in stimulus-reward associations: Studies using a second-order schedule of sexual reinforcement. Neuroscience, 30, 63-75.

FiSKE, D. W., \& MADDI, S. R. (Eds.) (1961). Functions of varied experience. Homewood, IL: Dorsey.

Foltin, R. W., \& Fischman, M. W. (1991). Smoked and intravenous cocaine in humans: Acute tolerance, cardiovascular and subjective effects. Journal of Pharmacology \& Experimental Therapeutics, 257, 247-261.

Gallistel, C. R. (1969). The incentive of brain-stimulation reward. Journal of Comparative \& Physiological Psychology, 69, 713-721.

Gallistel, C. R., STEllaR, J. R., \& Bubis, E. (1974). Parametric analysis of brain stimulation reward in the rat: $I$. The transient process and the memory-containing process. Journal of Comparative \& Physiological Psychology, 87, 848-859.

GerbeR, G. J., \& STRETCH, R. (1975). Drug-induced reinstatement of extinguished self-administration behavior in monkeys. Pharmacology, Biochemistry \& Behavior, 3, 1055-1061

Gerber, G. J., \& WISE, R. A. (1989). Pharmacological regulation of intravenous cocaine and heroin self-administration in rats: A variable dose paradigm. Pharmacology, Biochemistry \& Behavior, 32, 527 531.

Glickman, S. E., \& SchifF, B. B. (1967). A biological theory of reinforcement. Psychological Review, 74, 81-109.

GolDMAN-RAKIC, P. S. (1996). Regional and cellular fractionation of working memory. Proceedings of the National Academy of Sciences, 93, 13473-13480.

Goldman-Rakic, P. S., Bates, J. F, \& Chafee, M. V. (1992). The prefrontal cortex and internally generated motor acts. Current Opinion in Neurobiology, 2, 830-835.

Gratton, A., \& WISE, R. A. (1988a). Comparisons of connectivity and conduction velocities for medial forebrain bundle fibers subserving stimulation-induced feeding and brain stimulation reward. Brain Research, 438, 264-270.

Gratton, A., \& WiSE, R. A. (1988b). Comparisons of refractory periods for medial forebrain bundle fibers subserving stimulationinduced feeding and brain stimulation reward: A psychophysical study. Brain Research, 438, 256-263.
Harlow, H. F. (1953). Mice, monkeys, men and motives. Psychological Review, 60, 23-32.

HEBB, D. O. (1949). The organization of behavior. New York: Wiley. HeBB, D. O. (1955). Drives and the C.N.S. (conceptual nervous system). Psychological Review, 62, 243-254.

Heikkila, R. E., Orlansky, H., \& Cohen, G. (1975). Studies on the distinction between uptake inhibition and release of $\left[{ }^{3} \mathrm{H}\right]$ dopamine in rat brain tissue slices. Biochemical Pharmacology, 24, 847-852.

HiNDE, R. A. (1966). Animal behavior. New York: McGraw-Hill.

HIRSH, R. (1974). The hippocampus and contextual retrieval of information from memory: A theory. Behavioral Biology, 12, 421-444.

Hulk, C. L. (1943). Principles of behavior. New York: Appleton-CenturyCrofts.

Iglauer, C., Llewellyn, M. E., \& Woods, J. H. (1976). Concurrent schedules of cocaine injection in thesus monkeys: Dose variations under independent and non-independent variable-interval procedures. Pharmacological Reviews, 27, 367-383.

JAFFE, J. H. (1985). Drug addiction and drug abuse. In A. G. Gilman, L. S. Goodman, \& A. Gilman (Ed.), The pharmacological basis of therapeutics (pp. 532-581). New York: Macmillan.

JENCK, F., QUIRION, R., \& WISE, R. A. (1987). Opioid receptor subtypes associated with ventral tegmental facilitation and periaqueductal gray inhibition of feeding. Brain Research, 423, 39-44.

JENSEN, G. D. (1963). Preference for barpressing over "freeloading" as a function of number of rewarded presses. Journal of Experimental Psychology, 65, 451-454.

Johanson, C. E., Balster, R. L., \& Bonese, K. (1976). Selfadministration of psychomotor stimulant drugs: The effects of unlimited access. Pharmacology, Biochemistry \& Behavior, 4, 45-51.

Johnson, S. W., \& NORTH, R. A. (1992). Opioids excite dopamine neurons by hyperpolarization of local interneurons. Journal of Neuroscience, 12, 483-488.

Keefe, K. A., Sved, A. F., Zigmond, M. J., \& Abercrombie, E. D. (1993). Stress-induced dopamine release in the neostriatum: Evaluation of the role of action potentials in nigrostriatal dopamine neurons or local initiation by endogenous excitatory amino acids. Journal of Neurochemistry, 61, 1943-1952.

KESNER, R. P., \& HARDY, J. D. (1983). Long-term memory for contextual attributes: Dissociation of amygdala and hippocampus. Behavioural Brain Research, 8, 139-149.

Kоoв, G. F., Stinus, L., Le Moal, M., \& Bloom, F. E. (1989). Opponent process theory of motivation: Neurobiological evidence from studies of opiate dependence. Neuroscience \& Biobehavioral Reviews, 13, 135-140.

Kosten, T. R. (1998). Addiction as a brain disease. American Journal of Psychiatry, 155, 711-713.

LEEB, K., \& WISE, R. A. (1994). The effect of intravenous selfadministration of $d$ - and $l$-amphetamine on nucleus accumbens dopamine levels. Society for Neuroscience Abstracts, 20, 1622.

Li, D.-H., DepoORTERE, R. Y., \& EMMETT-OGLESBY, M. W. (1994). Tolerance to the reinforcing effects of cocaine in a progressive ration paradigm. Psychopharmacology, 116, 326-332.

LYNESS, W. H., FrIEDLE, N. M., \& MOORE, K. E. (1979). Destruction of dopaminergic nerve terminals in nucleus accumbens: Effect on $d$ amphetamine self-administration. Pharmacology, Biochemistry \& Behavior, 11, 553-556.

MaLmo, R. B. (1975). On emotions, needs, and our archaic brain. New York: Holt, Rinehart \& Winston.

MARGules, D. L., \& OldS, J. (1962). Identical "feeding" and "rewarding" systems in the lateral hypothalamus of rats. Science, 135, 374375 .

Markou, A., \& KooB, G. F. (1991). Postcocaine anhedonia: An animal model of cocaine withdrawal. Neuropsychopharmacology, 4, 17-26

MEIL, W. M., \& SEE, R. E. (1997). Lesions of the basolateral amygdala abolish the ability of drug associated cues to reinstate responding during withdrawal from self-administered cocaine. Behavioural Brain Research, 87, 139-148.

Mello, N. K., \& Mendelson, J. H. (1972). Drinking patterns during work-contingent and non-contingent alcohol acquisition. Psychosomatic Medicine, 34, 139-164. 
MENDElson, J. (1966). The role of hunger in the T-maze learning for food by rats. Journal of Comparative \& Physiological Psychology, 62, 341-349.

MilLeR, N. E. (1963). Some reflections on the law of effect produce a new alternative to drive reduction. Nebraska Symposium on Motivation, 11, 65-112.

Morgan, M. J. (1974). Resistance to satiation. Animal Behaviour, 22 , 449-466.

Nestler, E. J., \& Aghajanian, G. K. (1997). Molecular and cellular basis of addiction. Science, 278, 58-63.

NoEL, M. B., \& WISE, R. A. (1993). Ventral tegmental injections of morphine but not U-50,488H enhance feeding in food-deprived rats. Brain Research, 632, 68-73.

NoEL, M. B., \& Wise, R. A. (1995). Ventral tegmental injections of a selective $\mu$ or $\delta$ opioid enhance feeding in food-deprived rats. Brain Research, 673, 304-312.

Peoples, L. L., \& West, M. O. (1996). Phasic firing of single neurons in the rat nucleus accumbens correlated with the timing of intravenous cocaine self-administration. Journal of Neuroscience, 16 , 3459-3473.

Pfaffmann, C. (1960). The pleasures of sensation. Psychological Review, 67, 253-268.

Pickens, R. [W.], \& HaRris, W. C. (1968). Self-administration of $d$ amphetamine by rats. Psychopharmacologia, 12, 158-163.

Pickens, R. W., \& Johanson, C. E. (1992). Craving: Consensus of status and agenda for future research. Drug \& Alcohol Dependence, 30, 127-131.

Pickens, R. [W.], \& Thompson, T. (1968). Cocaine-reinforced behavior in rats: Effects of reinforcement magnitude and fixed-ratio size. Journal of Pharmacology \& Experimental Therapeutics, 161, 122-129.

Pocock, D., LeEB, K., \& WISE, R. A. (1994). Elevations and phasic fluctuations in nucleus accumbens dopamine during IV heroin selfadministration. Society for Neuroscience Abstracts, 20, 1234.

Richardson, N. R., Smith, A. M., \& RoberTs, D. C. S. (1994). A single injection of either flupenthixol decoanate or haloperidol decanoate produces long-term changes in cocaine self-administration in rats. Drug \& Alcohol Dependence, 36, 23-25.

Roberts, D. C. S., Corcoran, M. E., \& Fibiger, H. C. (1977). On the role of ascending catecholaminergic systems in intravenous selfadministration of cocaine. Pharmacology, Biochemistry \& Behavior, 6, 615-620.

RoberTs, D. C. S., \& KoOB, G. F. (1982). Disruption of cocaine selfadministration following 6-hydroxydopamine lesions of the ventral tegmental area in rats. Pharmacology, Biochemistry \& Behavior, 17, 901-904.

Roberts, D. C. S., KoOb, G. F., Klonoff, P., \& Fibiger, H. C. (1980). Extinction and recovery of cocaine self-administration following 6OHDA lesions of the nucleus accumbens. Pharmacology, Biochemistry \& Behavior, 12, 781-787.

Robins, L. N., Helzer, J. E., \& Davis, D. H. (1975). Narcotic use in southeast Asia and afterward: An interview study of 898 Vietnam returnees. Archives of General Psychiatry, 32, 955-961.

ROBINSON, T. E., \& BECKER, J. B. (1986). Enduring changes in brain and behavior produced by chronic amphetamine administration: A review and evaluation of animal models of amphetamine psychosis. Brain Research Reviews, 11, 157-198.

Robinson, T. E., \& Berridge, K. C. (1993). The neural basis of drug craving: An incentive-sensitization theory of addiction. Brain Research Reviews, 18, 247-292.

Romo, R., \& Schultz, W. (1990). Dopamine neurons of the monkey midbrain: Contingencies of responses to active touch during selfinitiated arm movements. Journal of Neurophysiology, 63, 592-606.

Rossetti, Z. L., Hmaidan, Y., Laj, M., \& Gessa, G. L. (1992). Marked fall in extraneuronal dopamine during behavioral despair in rats. Society for Neuroscience Abstracts, 18, 885.

SCHNEIRLA, T. C. (1959). An evolutionary and developmental theory of biphasic processes underlying approach and withdrawal. In M. R. Jones (Ed.), Nebraska Symposium on Motivation (pp. 1-42). Lincoln: University of Nebraska Press.
Schultz, W., Apicella, P., Scarnati, E., \& LuUngberg, T. (1992). Neuronal activity in monkey ventral striatum related to the expectation of reward. Journal of Neuroscience, 12, 4595-4610.

Schultz, W., \& Romo, R. (1990). Dopamine neurons of the monkey midbrain: Contingencies of responses to stimuli eliciting immediate behavioral reactions. Journal of Neurophysiology, 63, 607-624.

Shaham, Y., Rajabi, H., \& Stewart, J. (1996). Relapse to heroinseeking in rats under opioid maintenance: The effects of stress, heroin priming, and withdrawal. Journal of Neuroscience, 16, 19571963.

SHAHAM, Y., \& STEWART, J. (1995). Stress reinstates heroin-seeking in drug-free animals: An effect mimicking heroin, not withdrawal. Psychopharmacology, 119, 334-341.

SOLOMON, R. L., \& CoRBiT, J. D. (1973). An opponent-process theory of motivation: II. Cigarette addiction. Journal of Abnormal Psychology, 81, 158-171

SteIN, L., XUE, B. G., \& Belluzzi, J. D. (1994). In vitro reinforcement of hippocampal bursting: A search for Skinner's atoms of behavior. Journal of the Experimental Analysis of Behavior, 61, 155-168.

STEWART, J. (1984). Reinstatement of heroin and cocaine selfadministration behavior in the rat by intracerebral application of morphine in the ventral tegmental area. Pharmacology, Biochemistry \& Behavior, 20, 917-923.

STEWART, J., \& WISE, R. A. (1992). Reinstatement of heroin selfadministration habits: Morphine prompts and naltrexone discourages renewed responding after extinction. Psychopharmacology, 108, 79-84.

Sutherland, R. J., \& MCDonalD, R. J. (1990). Hippocampus, amygdala, and memory deficits in rats. Behavioural Brain Research, 37, 57-79.

ToATES, F. (1986). Motivational systems. Cambridge: Cambridge University Press.

Volkow, N. D., Wang, G. J., Fischman, M. W., Foltin, R. W., Fowler, J. S., Abumrad, N. N., Vitkun, S., Logan, J., Gatley, S. J., PAPPas, N., Hitzemann, R., \& Shea, C. E. (1997). Relationship between subjective effects of cocaine and dopamine transporter occupancy. Nature, 386, 827-830.

WISE, R. A. (1974). Lateral hypothalamic electrical stimulation: Does it make animals hungry? Brain Research, 67, 187-209.

WISE, R. A. (1978). Catecholamine theories of reward: A critical review. Brain Research, 152, 215-247.

WISE, R. A. (1982). Neuroleptics and operant behavior: The anhedonia hypothesis. The Behavioral \& Brain Sciences, 5, 39-87.

WISE, R. A. (1987a). Intravenous drug self-administration: A special case of positive reinforcement. In M. A. Bozarth (Ed.), Methods of assessing the reinforcing properties of abused drugs (pp. 117-141). New York: Springer-Verlag.

WISE, R. A. (1987b). Sensorimotor modulation and the variable action pattern (VAP): Toward a noncircular definition of drive and motivation. Psychobiology, 15, 7-20.

WISE, R. A. (1988). The neurobiology of craving: Implications for understanding and treatment of addiction. Journal of Abnormal Psychology, 97, 118-132.

Wise, R. A., \& Bozarth, M. A. (1987). A psychomotor stimulant theory of addiction. Psychological Review, 94, 469-492.

Wise, R. A., Newton, P., Leeb, K., Burnette, B., Pocock, D., \& JusTICE, J. (1995). Fluctuations in nucleus accumbens dopamine concentration during intravenous cocaine self-administration in rats. Psychopharmacology, 120, 10-20.

WISE, R. A., \& RoMPrE, P.-P. (1989). Brain dopamine and reward. Annual Review of Psychology, 40, 191-225.

Wise, R. A., Spindler, J., DEWIT, H., \& Gerber, G. J. (1978). Neuroleptic-induced "anhedonia" in rats: Pimozide blocks the reward quality of food. Science, 201, 262-264.

WoODS, J. H., \& SCHUster, C. R. (1971). Opiates as reinforcing stimuli. In T. Thompson \& R. Pickens (Eds.), Stimulus properties of drugs (pp. 163-175). New York: Appleton-Century-Crofts.

Yeomans, J. S., Mathur, A., \& Tampakeras, M. (1993). Rewarding brain stimulation: Role of tegmental cholinergic neurons that activate dopamine neurons. Behavioral Neuroscience, 107, 1077-1087. 
YOKEL, R. A. (1987). Intravenous self-administration: Response rates, the effects of pharmacological challenges, and drug preferences. In M. A. Bozarth (Ed.), Methods of assessing the reinforcing properties of abused drugs (pp. 1-33). New York: Springer-Verlag.

YoKel, R. A., \& PTCKENS, R. (1973). Self-administration of optical isomers of amphetamine and methylamphetamine by rats. Journal of Pharmacology \& Experimental Therapeutics, 187, 27-33.

YoKel, R. A., \& PICKENS, R. (1974). Drug level of $d$ - and $l$-amphetamine during intravenous self-administration. Psychopharmacologia, 34, 255-264.
YoKel, R. A., \& Wise, R. A. (1975). Increased leverpressing for amphetamine after pimozide in rats: Implications for a dopamine theory of reward. Science, 187, 547-549.

Zigmond, M. J., \& STricker, E. M. (1989). Animal models of Parkinsonism using selective neurotoxins: clinical and basic implications. International Review of Neurobiology, 31, 1-79.

(Manuscript received August 5, 1998 revision accepted for publication January 13, 1999.) 